\title{
Chemical and rheological properties of some Egyptian and Yemeni wheat varities (Abstract)
}

\author{
Ali Al-Mahturi' ${ }^{1}$, Ashraf M. Sharoba', Ahmed Ibrahim² and Mahmoud Hassan² \\ ${ }^{1}$ Department of Food Science, Faculty of Agriculture, Sana'a University, Republic of Yemen \\ ${ }^{2}$ Department of Food Technology, Faculty of Agriculture, Benha University, Qaluobia, Egypt.
}

Corresponding author: ashraf_sharoba@yahoo.com

\begin{abstract}
This study aimed to used new hard wheat verities of Yemeni wheat (Saba1 and Bohos 13) and Egyptian wheat (Masr1 and Gemmiza 11) to study the ability to use in production bread and bakery products. All varieties were milled and separation the extraction $72 \%$ at the same commercial condition in Egypt mills. The chemical composition and rheological properties was determined and the results show that the protein value was highest in Bohos 13 and lowest in Saba1, the fiber value was similar in all varieties, the high value of ash was with Saba1 and low value was with Gemmiza 11. The rheological properties measured by the old methods (farinograph and extensograph) and new methods (mixolab and alveograph). The results from farinograph showed the highest stability value was with Masr1 (12.5 min) and the lowest value was with Bohos 13 (2.5 min), at the same way the extensograph results were high with Masr1 and low with Bohos 13. The results which obtained from mixolab and alveograph indicate the similar results with farinograph and extensograph. So this study recommends increasing of cultivation and using of Masr1 and Saba1in bakery products.
\end{abstract}

Keywords: Wheat varieties, Rheological properties, Chemical composition. 
